\section{Evaluation of the fixation duration in visual search}

\section{KIRK MOFFITT \\ Systems Research Laboratories, Inc., Dayton, Ohio}

Vaughan and Graefe (1977) proposed that visual fixation duration measures during visual search are confounded by two factors, cognitive processing time and time required by the oculomotor system to initiate the next eye movement, the oculomotor latency. It was concluded that, under some conditions, the fixation duration is independent of the visual information available to the eye during the fixation. That is, the oculomotor latency exceeds the information processing time. This independence was found to occur in a relatively simple recognition task involving one display item per fixation. In a visual search involving relatively high information display items, or where several items are included in each fixation, the oculomotor latency would not be expected to determine the fixation duration.

This proved to be the case in a study by Mackworth (1976) in which several items were included in each fixation. Subjects searched a strip of several rows of circles for a square target. Display density increased with the number of circles in the strip. By counting the number of eye movements made on each strip, the number of circles per fixation was estimated. Above four circles per fixation, both the fixation duration and the number of circles per fixation tended to increase with display density. Mackworth attributed the increase in fixation duration to the extra cognitive demand added by the need to process more nontarget circles during each fixation.

An alternate method of estimating the number of display items per fixation is to construct a display that controls this factor. Mocharnuk (1978) had subjects search a display consisting of clusters of letters. It was likely that each fixation would accommodate one cluster. As expected, fixation duration increased with the number of letters per cluster. A fixation duration effect was also found by Moffitt (Note 1), who varied the information content of each display item while controlling the number of items per fixation. Subjects scanned back and forth between two changing display items, located 10 deg of visual angle apart, searching for a member of the memory set. Given the size of each display item, $.22 \mathrm{deg}$ of visual

The author thanks Evelyn Williams for commenting on this paper. Requests for reprints should be sent to Kirk Moffitt, Systems Research Laboratories, Inc., 2800 Indian Ripple Road, Dayton, Ohio 45440. angle, and the distance between items, it is unlikely that more than one item was processed during each fixation. The major finding was that the fixation duration increased as a function of memory set size. It was concluded that the fixation duration reflects the amount of information being processed.

The studies cited demonstrate that the fixation duration will increase as a result either of increasing the number of items per fixation while holding the information value of each item constant or of increasing the information value of each item while holding the number of items per fixation constant. The case where the information value per item is varied and the number of items processed during each fixation is not controlled for would set the stage for a potential confounding. Consider two displays, one with simple and one with complex items. It is likely that the search rate would be fastest for the simple display. Given the case where more items were included in each fixation for the simple display, the fixation duration would be relatively insensitive to display complexity. Such a case would result if increased processing demands, which would decrease the processing rate, caused the useful field of view to narrow. Such a narrowing has been found to result from increased foveal loads (lkeda \& Takeuchi, 1975). Narrowing of the useful field of view would be expected to have the greatest effect on performance for displays which allow multiple items to be processed during each fixation, that is, high-density displays.

A review of the literature turned up 11 visual search studies which measured eye movements and which also provided a description of the display from which item size and interitem distance could be estimated. Most of these studies employed displays which forced an ordered, rather than a random, search pattern. This disallows the common method of computing display density, dividing the number of items by the total area. A measure of ordered display density was computed by dividing item size by interitem distance. This measure takes into account the inverse relationship of visual resolution with detail size and the distance of the retinal image from the center of the fovea (Bouma, 1978; Newman, 1975).

Table 1 presents the 11 studies ranked in order of increasing density. The right-hand column indicates whether the fixation duration was found to be dependent on the experimental manipulation. That is, did the fixation duration vary with such manipulations as memory set size, display complexity, developmental level, coding, and target/nontarget similarity? As can be seen, the higher density displays tended not to show a fixation duration dependence. The inconsistent fixation duration results of Spragins, 
Table 1

Display Descriptions

\begin{tabular}{|c|c|c|c|c|c|}
\hline Study & $\begin{array}{c}\text { Item Size } \\
\text { (Average of } \\
\text { horizontal and } \\
\text { vertical extents)* }\end{array}$ & $\begin{array}{l}\text { Interitem } \\
\text { Distance } \\
\text { (Center to } \\
\text { center)* }\end{array}$ & $\begin{array}{c}\text { Display Density } \\
\text { (Item size } \div \\
\text { interitem } \\
\text { distance) }\end{array}$ & $\begin{array}{c}\text { Item } \\
\text { Description }\end{array}$ & $\begin{array}{l}\text { Was the Fixation } \\
\text { Duration Dependent on } \\
\text { the Experimental } \\
\text { Manipulation? }\end{array}$ \\
\hline Moffitt (Note 1) & .22 & 10.00 & .02 & digit & yes \\
\hline Gould (1973) & .20 & 3.67 & .05 & letter & yes \\
\hline Gould \& Peeples (1970) & 1.50 & 8.50 & .18 & line pattern & yes \\
\hline Gould (1967) & 1.55 & 6.65 & .23 & asterisk pattern & yes \\
\hline Gould \& Schaffer (1967) & 1.50 & 6.50 & .23 & asterisk pattern & yes \\
\hline Gould \& Dill (1969) & 2.00 & 7.50 & .27 & asterisk pattern & yes \\
\hline Mocharnuk (1978) & 1.80 & $15-5$ & $.12-.36$ & cluster of letters & yes** \\
\hline Gould \& Schaffer (1965) & 1.12 & 3.00 & .37 & digit & no \\
\hline Luria \& Strauss (1975) & 5.95 & 13.82 & .43 & dial & no \\
\hline Gordon (1969) & .40 & .60 & .67 & letter & no \\
\hline Spragins, Lefton, \& Fisher (1976) & 2.00 & 2.50 & .80 & word & mixed results \\
\hline
\end{tabular}

*Wen incomplete information was provided, estimates were made. Measures are expressed in degrees of visual angle.

**Experiment 3-number of items per cluster.

Table 2

Reanalysis of the Data

\begin{tabular}{|c|c|c|c|c|c|c|}
\hline Study & $\begin{array}{c}\text { Display } \\
\text { Size }\end{array}$ & $\begin{array}{c}\text { Experimental } \\
\text { Condition }\end{array}$ & $\begin{array}{c}\text { Search Rate } \\
\text { (Items/Second) }\end{array}$ & $\begin{array}{l}\text { Fixation } \\
\text { Duration }\end{array}$ & $\begin{array}{c}\text { Fixations/ } \\
\text { Display }\end{array}$ & $\begin{array}{c}\text { Items/ } \\
\text { Fixation }\end{array}$ \\
\hline Gordon (1969) & 1000 & $\begin{array}{l}\text { one distractor } \\
\text { two distractors } \\
\text { three distractors }\end{array}$ & $\begin{array}{r}12.82 \\
10.00 \\
8.40\end{array}$ & $\begin{array}{l}.310 \\
.340 \\
.330\end{array}$ & $\begin{array}{l}232 \\
276 \\
336\end{array}$ & $\begin{array}{l}4.31 \\
3.62 \\
2.98\end{array}$ \\
\hline Luria \& Strauss (1975) & $8^{*}$ & $\begin{array}{l}\text { color coded } \\
\text { color and shape } \\
\text { shape } \\
\text { uncoded }\end{array}$ & $\begin{array}{l}6.35 \\
3.92 \\
3.15 \\
3.13\end{array}$ & $\begin{array}{l}.210 \\
.230 \\
.210 \\
.170\end{array}$ & $\begin{array}{l}2.76 \\
3.90 \\
5.75 \\
8.13\end{array}$ & $\begin{array}{r}2.90 \\
2.05 \\
1.39 \\
.98\end{array}$ \\
\hline Spragins, Lefton, \& Fisher (1976) & & $\begin{array}{l}\text { adult**} \\
\text { Grade } 5^{* *} \\
\text { Grade } 3^{* *}\end{array}$ & $\begin{array}{l}7.25 \\
3.93 \\
2.68\end{array}$ & $\begin{array}{l}.244 \\
.282 \\
.276\end{array}$ & & $\begin{array}{r}2.19 \\
1.31 \\
.84\end{array}$ \\
\hline
\end{tabular}

*On the average only half of the 16-item display would have to be searched since the trial ends when the target is found.

**Normal spacing and case.

Lefton, and Fisher (1976) are difficult to explain. This is at least partly due to the complex experimental manipulations: normal vs. alternating case with normal, filled, or absent spacing between words. For reanalysis purposes, the most straightforward condition was chosen, normal case with normal spacing.

Table 2 provides a reanalysis of those studies described in Table 1 which did not show a fixation duration dependence and which also provided sufficient data for computation of the number of items processed during each fixation. In each case, search rate, the performance measure, was dependent on the experimental manipulations. This is in contrast to the fixation duration results. As predicted, the number of items processed during each fixation covaried with the search rate.

These findings point to the need to consider display attributes when evaluating fixation duration measures. Specifically, the fixation duration should be treated as a confounded variable in high-density displays. Both the number of items included in each fixation and the rate at which they are processed should be evaluated with the fixation duration in such displays. If the fixation duration is the variable of major interest, dense displays should be avoided.

For a sparse display which requires an eye movement to acquire each item or cluster of items, the fixation duration would be adjusted to permit the information to be processed while the saccade extent would be determined by the distance between items or clusters of items. The fixation duration would be expected to increase with item information and/or cluster numerosity. A high-density display would allow a more flexible strategy where the fixation duration and/or the saccade extent could be adjusted during a visual search. The studies that were reanalyzed indicate that the saccade extent is varied, allowing the fixation duration to remain relatively constant. 


\section{REFERENCE NOTE}

Moffitt, K. W. Eye movements as a correlate of information processing in a visual-search task (Tech. Rep. 78-3). Las Cruces: New Mexico State University, Human Performance Laboratory, 1978.'

\section{REFERENCES}

Bouma, H. Visual search and reading: Eye movements and functional visual field: A tutorial review. In J. Requin (Ed.), Attention and performance VII. Hillsdale, N. J.: Erlbaum, 1978.

Gordon, I. E. Eye movements during search through printed lists. Perceptual and Motor Skills, 1969, 29, 683-686.

GouLD, J. D. Pattern recognition and eye-movement parameters. Perception \& Psychophysics, 1967, 2, 399-407.

Gould, J. D. Eye movements during visual search and memory search. Journal of Experimental Psychology, 1973, 98, 184-195.

Gould, J. D., \& Dill, A. B. Eye-movement parameters and pattern discrimination. Perception \& Psychophysics, 1969, 6, 311-320.

Gould, J. D., \& Peeples, D. R. Eye movements during visual search and discrimination of meaningless, symbol, and object patterns. Journal of Experimental Psychology, 1970, 85, 51-55.

Gould, J. D., \& Schaffer, A. Eye-movement patterns in scanning numeric displays. Perceptual and Motor Skills, 1965, 20, 521-535.
Gould, J. D., \& Schaffen, A. Eye-movement parameters in pattern recognition. Journal of Experimental Psychology, 1967, 74, 225-229.

IKEDA, M., \& TAKEUCHI, T. Influence of foveal load on the functional visual field. Perception \& Psychophysics, 1975, 18, 255-260.

Luria, S. M., \& Strauss, M. S. Eye movements during search for coded and uncoded targets. Perception \& Psychophysics, 1975, 17, 303-308.

Mackworth, N. H. Stimulus density limits the useful field of view. In R. A. Monty \& J. W. Senders (Eds.), Eye movements and psychological processes. Hillsdale, N.J.: Erlbaum, 1976.

MocharnUK, J. B. Visual target acquisition and ocular scanning performance. Human Factors, 1978, 20, 611-631.

Newman, M. Visual acuity. In. R. A. Moses (Ed.), Physiology of the eye. St. Louis: C. V. Mosby, 1975.

Spragins, A. B., Lefton, L. A., \& Fisher, D. F. Eye movements while reading and searching spatially transformed text: A developmental examination. Memory \& Cognition, 1976, 4, 36-42.

Vaughan, J., \& Graefe, T. M. Delay of stimulus presentation after the saccade in visual search. Perception \& Psychophysics, 1977, 22, 201-205.

(Received for publication February 1, 1980; accepted February 5, 1980.) 